\title{
Melanosis Coli Due to Aloe Vera Consumption
}

\author{
Masaya Iwamuro ${ }^{1}$, Takehiro Tanaka ${ }^{2}$ and Hiroyuki Okada ${ }^{1}$
}

Key words: colonoscopy, melanosis coli, aloe vera, anthraquinone-containing product

(Intern Med 59: 2633-2634, 2020)

(DOI: 10.2169/internalmedicine.5183-20)

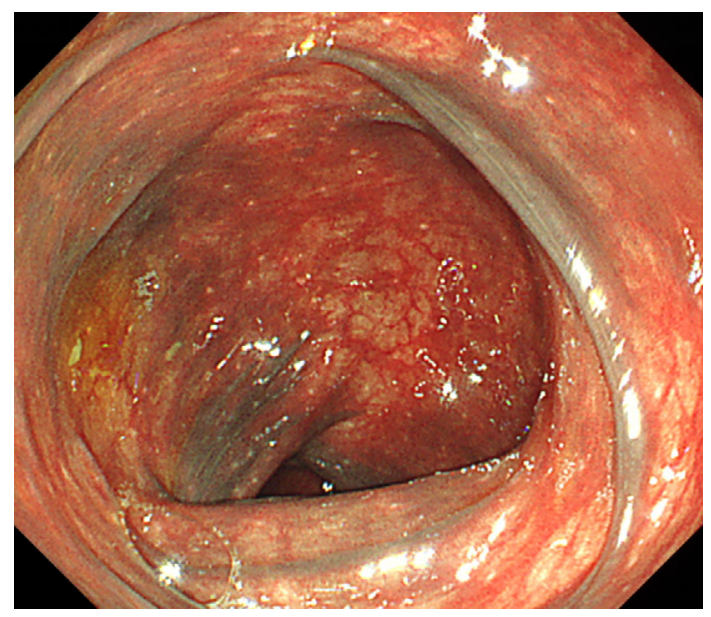

Picture 1.

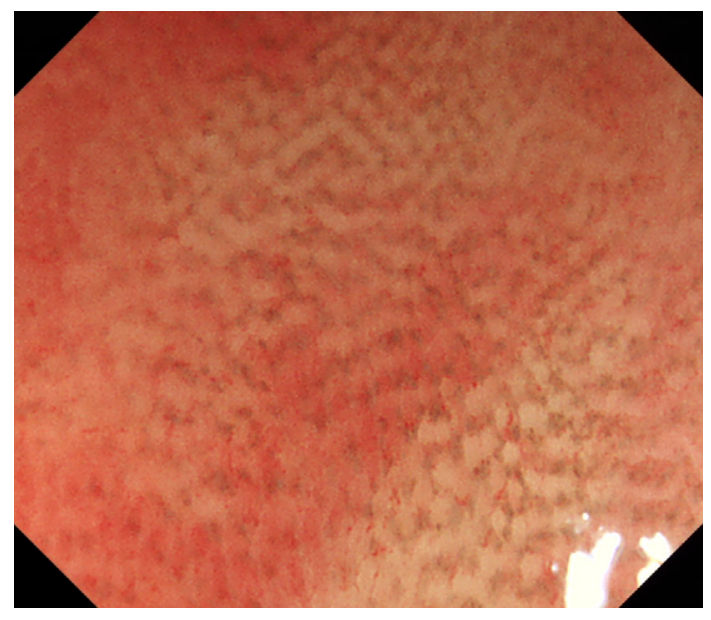

Picture 3.

A 63-year-old Japanese man underwent colonoscopy for the investigation of right flank pain. He had been taking amlodipine. On colonoscopy, black pigmentation was observed

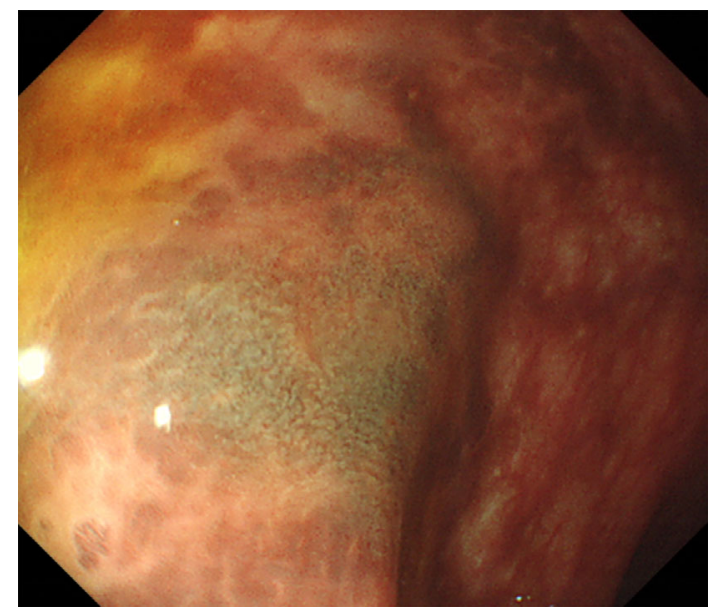

Picture 2.

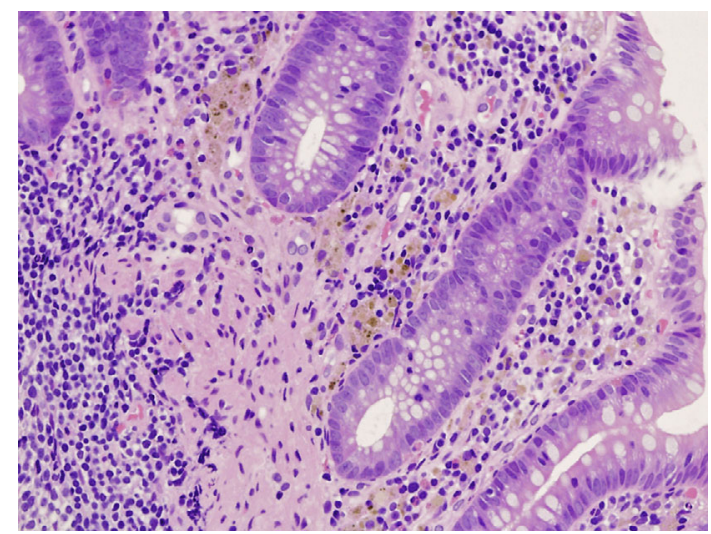

Picture 4.

throughout the large intestine, i.e., cecum, colon (Picture 1,2), and rectum. Magnifying observations revealed that the black color change existed in the intervening part of the intestinal mucosa (Picture 3). A histopathological examination revealed the deposition of a dark melanin-like pig-

${ }^{1}$ Department of Gastroenterology and Hepatology, Okayama University Graduate School of Medicine, Dentistry, and Pharmaceutical Sciences, Japan and ${ }^{2}$ Department of Pathology, Okayama University Hospital, Japan

Received: April 27, 2020; Accepted: May 20, 2020; Advance Publication by J-STAGE: July 7, 2020

Correspondence to Dr. Masaya Iwamuro, iwamuromasaya@yahoo.co.jp 
ment in the lamina propria (Picture 4). Although he initially denied having taken laxatives, the endoscopist suspected the intake of an anthraquinone-containing agent or food. Repeated interviews with the patient during the colonoscopy examination revealed the daily consumption of aloe vera powder for 2 years to promote regular bowel movements. Therefore, a diagnosis of melanosis coli due to aloe vera consumption was made for which no treatment was initiated. This case underscores the importance of careful history taking regarding the consumption of anthraquinone-containing products, beverages, and supplements, as well as laxative and herbal medicine use, in patients with discoloration of the colonic mucosa, because the long-term intake of anthraquinone-containing plant extracts of aloe vera, senna, and rhubarb can cause pigment deposition and discoloration of the colonic mucosa (1). Several studies have indicated a possible relationship between melanosis coli and a higher incidence and number of colonic non-adenoma polyps and low-grade adenomas $(2,3)$. Although this issue needs further investigation, the detection and follow-up of melanosis coli, in combination with reducing the consumption of the causative agent, may be clinically important.

The authors state that they have no Conflict of Interest (COI).

\section{References}

1. Li XA, Zhou Y, Zhou SX, et al. Histopathology of melanosis coli and determination of its associated genes by comparative analysis of expression microarrays. Mol Med Rep 12: 5807-5815, 2015.

2. Wang S, Wang Z, Peng L, et al. Gender, age, and concomitant diseases of melanosis coli in China: a multicenter study of 6,090 cases. PeerJ 6: e4483, 2018.

3. Liu ZH, Foo DCC, Law WL, et al. Melanosis coli: Harmless pigmentation? A case-control retrospective study of 657 cases. PLoS One 12: e0186668, 2017.

The Internal Medicine is an Open Access journal distributed under the Creative Commons Attribution-NonCommercial-NoDerivatives 4.0 International License. To view the details of this license, please visit (https://creativecommons.org/licenses/ by-nc-nd/4.0/).

(C) 2020 The Japanese Society of Internal Medicine Intern Med 59: 2633-2634, 2020 